\title{
Production of Endopolysaccharides from Malaysia's Local Mushrooms in Air-Lift Bioreactor
}

\author{
Shaiful Azuar Mohamad1*, Mat Rasol Awang1, Rusli Ibrahim¹, Choong Yew Keong2, \\ Mohd Yusof Hamzah', Rosnani Abdul Rashid', Sobri Hussein', Khairuddin Abdul Rahim¹, \\ Fauzi Daud ${ }^{3}$, Aidil Abdul Hamid³, Wan Mohtar Wan Yusoff ${ }^{3}$ \\ ${ }^{1}$ Agrotechnology and Biosciences Division, Malaysian Nuclear Agency, Bangi, Malaysia \\ ${ }^{2}$ Herbal Medicine Research Centre, Institute For Medical Research, Kuala Lumpur, Malaysia \\ ${ }^{3}$ Faculty of Science and Technology, Universiti Kebangsaan Malaysia, Bangi, Malaysia \\ Email: *azuar@nuclearmalaysia.gov.my
}

Received 17 June 2015; accepted 17 July 2015; published 20 July 2015

Copyright (C) 2015 by authors and Scientific Research Publishing Inc.

This work is licensed under the Creative Commons Attribution International License (CC BY). http://creativecommons.org/licenses/by/4.0/

c) (i) Open Access

\section{Abstract}

Four local mushroom species, viz. Auricularis polytricha, Lentinus edodes, Agrocybe sp and Pleurotus flabellatus were grown under submerged culture and screened for endopolysaccharides. The fermentation was done in $250 \mathrm{ml}$ working volume Erlenmeyer flask and the fermentation curves for all species were established. Pleurotus flabellatus has the highest rate of biomass production at the rate of $0.180 \mathrm{~g} / \mathrm{L} / \mathrm{day}$, at 10 days hence chosen for further investigation. Two additional media, viz. Mushroom Complete Media (MCM) and Yeast Malt (YM) were selected to be compared with potato extract(PE) media used initially. MCM media produced the highest biomass productivity at the rate of $0.311 \mathrm{~g} / \mathrm{L} / \mathrm{day}$. Pleurotus flabellatus biomass was extracted using modified Mizuno method and the endopolysaccharide obtained was tested for $\beta$-glucan. The yield of $\beta$-glucan was $7.70 \pm 1.11 \mathrm{~g} / 100 \mathrm{~g}$. The polysaccharides were purified using column chromatography to yield four fractions. The fourth fraction $F_{4}$, gave the highest molecular weight at $3.058 \times 10^{6}$ Dalton $(11.8 \%)$ and $1.282 \times 10^{4}$ Dalton $(88.2 \%)$. The mushroom, $P$. flabbelatus was cultured using air-lift bioreactor, and the highest productivity was obtained at air-flowrate $2 \mathrm{~L} / \mathrm{min}$, yielding $2.25 \mathrm{~g} / \mathrm{L} / \mathrm{day}$. The yield of biomass against substrate used (glucose consumption) $Y_{b / s}$ was $0.78 \mathrm{~g} / \mathrm{g}$.

\section{Keywords}

Submerged Culture Fermentation, Mushroom, $\beta$-Glucan, Column Chromatography, Molecular Weight

\footnotetext{
${ }^{*}$ Corresponding author.

How to cite this paper: Mohamad, S.A., Awang, M.R., Ibrahim, R., Keong, C.Y., Hamzah, M.Y., Rashid, R.A., Hussein, S., Rahim, K.A., Daud, F., Hamid, A.A. and Yusoff, W.M.W. (2015) Production of Endopolysaccharides from Malaysia's Local Mushrooms in Air-Lift Bioreactor. Advances in Bioscience and Biotechnology, 6, 456-462.

http://dx.doi.org/10.4236/abb.2015.67046
} 


\section{Introduction}

$\beta$-glucan obtained from mushrooms have been used as source of therapeutic agents functioning by modulating animal and human response and inhibiting certain tumor growth [1]-[3]. The mushroom derived polysaccharides can reduce the side effects significantly when take prior to and during radiotherapy/chemotherapy treatments [4]. Several polysaccharides including schizophyllan, lentinan, grifolan, krestin and polysaccharide-K (PSK) have been commercialized for clinical treatments of patients undergoing therapy [2]. Several reports about commercial products showed that Krestin which was derived from mycelium of Trametes versicolor had a molecular weight of $1.0 \times 10^{5}$ Dalton, Lentinan from fruit body of Lentinus edodes with $5.0 \times 10^{5}$ Dalton and Sonifilan from broth of Schizopyllum commune with $4.5 \times 10^{5}$ Dalton [3] [5]. This paper will focus on screening of $\beta$-glucan for local mushrooms grown under submerged culture fermentation.

The time taken to produce fruit bodies in solid state fermentation (SSF) often varies and especially for some medicinal mushrooms, the length tend to be longer. Submerged culture fermentation (SCF) has the advantage of producing higher quantity of mycelium, in a compact space, shorter incubation time and less contamination [6] [7]. The air-lift bioreactor will be used to compare biomass production in shake flasks.

$\beta$-glucan from local mushrooms will contribute to the development of the local industry if the productivity of SCF can be improved. This can be achieved by ensuring the productivity of the mycelium related to the endopolysaccharides production to produce at least $5 \% \mathrm{w} / \mathrm{w}$ of endopolysaccharides with different media.

\section{Methodology}

\subsection{Biological Materials}

The mushroom strains were collected by the Bioprocess Group, Agrotechnology and Biotechnology Division, Malaysian Nuclear Agency. The strains were maintained on potato-dextrose-agar (PDA) and subcultured every 3 months. Four local species of mushrooms tested were Auricularia polytricha, Lentinus edodes, Agrocybe sp and Pleurotus flabellatus due to its availability at the Nuclear Malaysia (NM) Mushroom Culture Collection and various reports showed the presence of $\beta$-glucan for all species.

\subsection{Screening for High Biomass Species}

The stock cultures of the species were transferred into the petri dish with PDA as the medium. Then $1 \mathrm{~cm}$ of the agar plate culture, was cut with a sterilized cutter and tranferred into a $500 \mathrm{ml}$ Erlenmeyer flask containing 250 $\mathrm{ml}$ of media incubated using orbital shaker at $50 \mathrm{rpm}$, at room temperature of $25^{\circ} \mathrm{C}$. The composition of media consists of potato extract $(100 \mathrm{~g} / \mathrm{l})$ and glucose $(30 \mathrm{~g} / \mathrm{l})$. The biomass was collected after 4, 6, 8, 10, 12, 14 and 16 days to obtain fermentation curves for all species.

\subsection{Screening of Media}

Based on literature, the media used were Mushroom Complete Media (MCM) which consists of $20 \mathrm{~g} / \mathrm{l}$ glucose, $2 \mathrm{~g} / \mathrm{l}$ meat peptone, $2 \mathrm{~g} / \mathrm{l}$ yeast extract, $0.46 \mathrm{~g} / \mathrm{l} \mathrm{KH}_{2} \mathrm{PO}_{4}, 1 \mathrm{~g} / \mathrm{l} \mathrm{K} \mathrm{HPO}_{4}$, and $0.5 \mathrm{~g} / \mathrm{l} \mathrm{MgSO}_{4} \cdot 7 \mathrm{H}_{2} \mathrm{O}$. Yeast Malt (YM) consists of $10 \mathrm{~g} / \mathrm{l}$ glucose, $3 \mathrm{~g} / \mathrm{l}$ yeast extract, $3 \mathrm{~g} / \mathrm{l}$ malt extract, and $5 \mathrm{~g} / \mathrm{l}$ meat peptone. The fermentation curves of these media were compared to the initial media used.

\subsection{Characterization}

\subsubsection{Hot Water Extraction to Produce Endopolysaccharides}

The biomass (100 g) produced was extracted to obtain the endopolysaccharides using modified Mizuno method [8], involving hot water extraction for at least $2 \mathrm{~h}$, filtration, concentration process and centrifugation. The supernatant was added to absolute ethanol (ratio 1:1) and kept overnight before lyophilization to get the polysaccharides.

\subsubsection{Endopolysaccharide and $\beta$-Glucan Determination}

The endopolysaccharide was tested using Mushroom and Yeast Beta Glucan Assay Procedure (Megazyme International Ireland Limited, 2008). The total beta glucan was obtained by hydrolysing the sample in concentrated $\mathrm{HCl}(37 \% \mathrm{v} / \mathrm{v}, \sim 10 \mathrm{M})$, followed by neutralization with $\mathrm{KOH}(2 \mathrm{M})$ and filtration with Whatman GF/A 
glass fibre filter paper before enzymatic hydrolysis by exo-1,3 $\beta$ glucanase and $\beta$-glucosidase. The $\alpha$-glucan was obtained after the sample was hydrolysed with $2 \mathrm{M} \mathrm{KOH}$ followed by enzymatic hydrolysis using amyglucosidase and invertase, then filtration with Whatman No.1 filter paper. Both reactions above were reacted with Glucose Oxidase and Peroxidase (GOPOD) before measurement using UV Spectrophotometer at $510 \mathrm{~nm}$.

\subsubsection{Column Chromatography}

The endopolysaccharides obtained from the extraction process were fractionated using Toyopearl DW-65F in column chromatography. Toyopearl DW-65F was diluted in phosphate buffer $(0.05 \mathrm{M}$ sodium dihidrogen phospate, $0.05 \mathrm{M}$ of disodium hydrogen phosphate, and $0.1 \mathrm{M}$ sodium chloride in $1 \mathrm{~L}$ of deionized water) and packed in a column. The fractions of endopolysaccharides sample obtained from the packed column were collected every 4 min and tested using phenol sulphuric acid test and its absorbance was measured at $490 \mathrm{~nm}$.

\subsubsection{Endopolysaccharides Molecular Weight Determination}

Average weight of endopolysaccharides, $\mathrm{M}_{\mathrm{w}}$, was determined by GPC-MALLS (Gel permeation Chromatography-Multiangle Laser Light Scattering). The GPC system comprised an Agilent G1310A pump (Agilent Tecnologies, Santa Clara, USA), an Agilent G1329A auto-injector with an injection loop of $100 \mu \mathrm{L}$ and a Wyatt 986 refractometer (Wyatt Technology, Santa Barbara, USA). The MALLS apparatus has a Wyatt Dawn-Heleos II laser photometer (Wyatt Technology, Santa Barbara, USA) equipped with a K5 flow cell and a He-Ne laser operating at $\mathrm{k}=632.8 \mathrm{~nm}$. An aqueous SEC column: Shodex OHpak SB-806 HQ $(8.0 \mathrm{~mm} \times 300 \mathrm{~mm})$ (Showa Denko, Kawasaki, Japan) was used for the analysis.

The mobile phase consisted of a filtered $(0.22 \mu \mathrm{m})$ phosphate buffer $(0.05 \mathrm{M}$ sodium dihidrogen phospate, $0.05 \mathrm{M}$ of disodium hydrogen phosphate, and $0.1 \mathrm{M}$ sodium chloride in $1 \mathrm{~L}$ deionized water) solution obtained using ultrapure water. The flow rate was $0.5 \mathrm{~mL} / \mathrm{min}$ and analyses were performed at room temperature. The samples were dissolved in phosphate buffer solution and filtered $(0.45 \mu \mathrm{m})$ to eliminate dust particles. The MALLS instrument was placed directly after the GPC columns and before the refractive index detector (DRI). Prior to measurements, a Dawn apparatus was calibrated using HPLC grade toluene and normalized using a 20 nm polystyrene latex standard (Thermo Scientific, Fremont, USA) in phosphate buffer solution. The performance of the HPSEC-MALLS system was checked with monodisperse pullulan of various molecular weights. A dn/dc value of 0.148 for $\beta$-glucan was used at wavelength $490 \mathrm{~nm}$ [9]. Data were collected from the DRI and MALLS and evaluated with the ASTRA software 5.3.4.14. Since $\beta$-glucans are polydisperse polysaccharides, average weights were compared. Results were estimated using second-order Zimm model.

\subsection{Production in Air Lift Bioreactor (Submerged Culture Fermentation)}

The $250 \mathrm{ml}$ of mycelia biomass ( $500 \mathrm{ml}$ shake flask) in MCM media was transferred to a $2.5 \mathrm{~L}$ working volume air lift bioreactor ( $5 \mathrm{~L}$ total volume) aseptically. The flow rates were varied from $0.5 \mathrm{~L} / \mathrm{min}$ to $2.0 \mathrm{~L} / \mathrm{min}$. (vvm 0.2 to 0.8 ). The mycelia produced from the submerged culture fermentation were freeze-dried until constant weight. The mycelial biomass dry weights obtained were plotted against air flow rate inlet.

\section{Results}

\subsection{Screening for High Biomass Species}

The fermentation curves for all species were plotted and shown in Figure 1.

Figure 1 shows mycelia growth profiles in submerged culture fermentation for the four species selected using potato extract as the crude media. The biomass collected ranged from approximately $0.1 \mathrm{~g}$ to $0.7 \mathrm{~g}$. As the fermentation duration increased, more media were consumed to produce more biomass. P. flabellatus produced the most consistent rate and highest biomass production whilst $L$. edodes species showed the lowest biomass production rate. The production rate of Agrocybe $s p$ was slightly lower than $P$. flabellatus whilst the rate of $A$. polytricha was initially low but increased at the end of fermentation. The most consistent production was by $P$. flabellatus, with the highest rate of biomass production at $0.180 \mathrm{~g} / \mathrm{L} /$ day, at the fermentation duration of 10 days.

\subsection{Screening of Media}

Figure 2 shows the mycelial growth profile for $P$. flabellatus using two additional media obtained from the lite- 


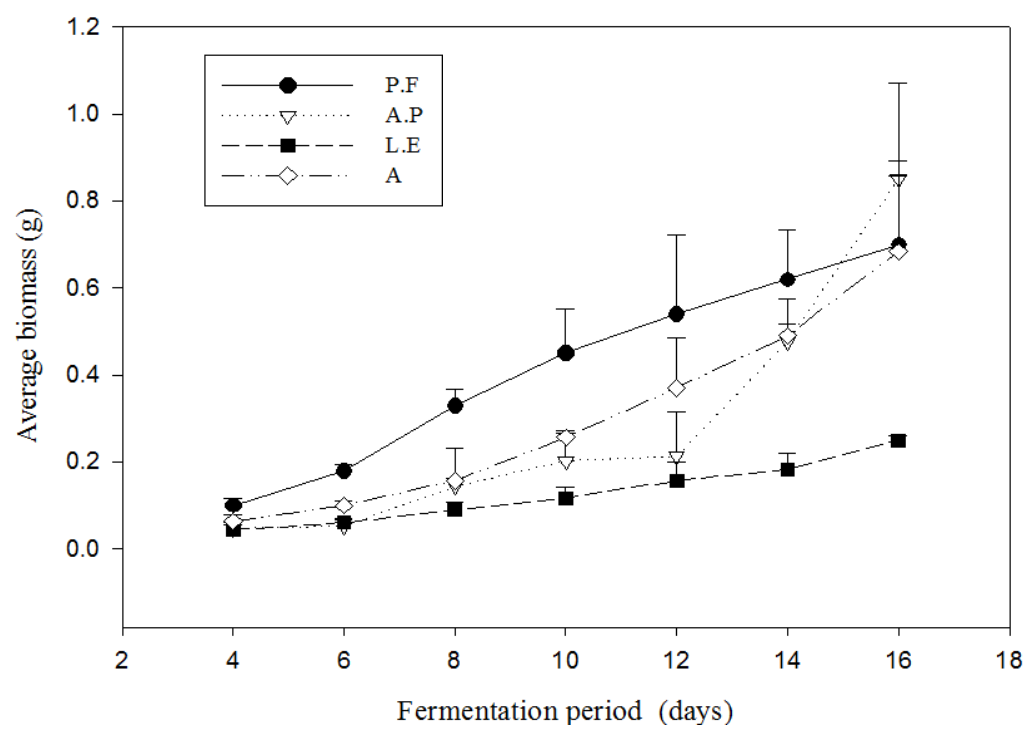

Figure 1. Fermentation curves for Agrocybe sp, Auricularia polytricha, Lentinus edodes, and Pleurotus flabellatus.

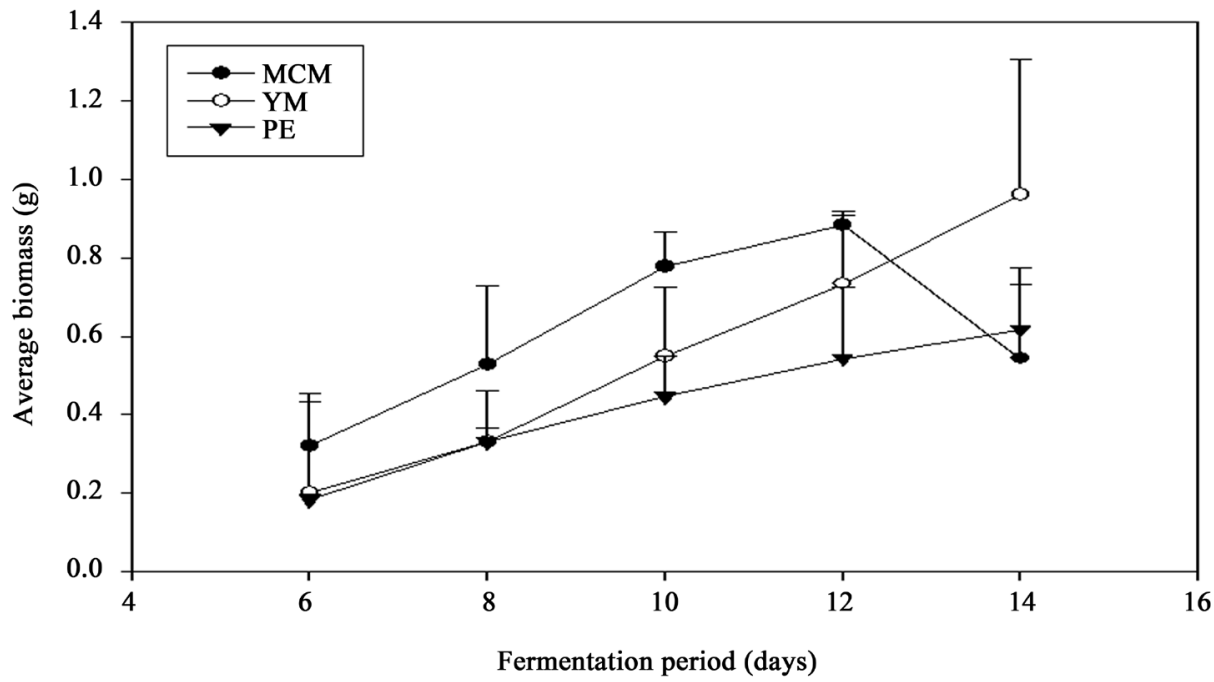

Figure 2. The fermentation curve of $P$. flabellatus using different media compared to the potato extract media.

rature compared to the initial potato extract media used. The two media produced more biomass compared to the crude media of potato extract. YM produced the most consistent rate but the production rate for MCM was higher than YM up to day 12. The calculation for each media and duration is shown in Table 1.

From the table, the highest production rate was $0.311 \mathrm{~g} / \mathrm{L} /$ day using media MCM, and again the fermentation period of 10 days. Using this media the production rate increased by $72.7 \%$. Hence, MCM was chosen for subsequent experiment.

\subsection{Characterization of Polysaccharides}

\subsection{1. $\beta$-Glucan Determination}

After the extraction process using Modified Mizuno method, $100 \mathrm{mg}$ of polysaccharide from the mycelium of $P$. flabellatus sample was used to test the presence of beta glucan using the beta glucan assay kit (Table 2). The total glucan and $\alpha$-glucan were obtained from the test done. The amount of $\beta$-glucan was obtained by subtraction of $\alpha$-glucan from the total glucan. The total glucan in the biomass was $17.54 \pm 2.91 \mathrm{~g} / 100 \mathrm{~g}$ whilst beta glucan yield was $7.70 \pm 1.11 \mathrm{~g} / 100 \mathrm{~g}$. No publication has reported this finding for the species studied. 


\subsubsection{Column Chromatography and Molecular Weight Determination}

From the column chromatography, the value of absorbance from each fractions obtained from phenol sulphuric acid test were plotted against the number of bottles collected at 4 min interval from the column as shown in Figure 3. Samples from bottle 6 - 14, 15 - 21, 25 - 37 and 38 - 60 were combined to give fraction $F_{1}, F_{2}, F_{3}$ and $\mathrm{F}_{4}$, respectively, to be analyzed further.

The four fractions were run in GPC-MALLS to determine the molecular weight. The $\mathrm{F}_{4}$ has the highest molecular weight with two possible molecular weight $3.058 \times 10^{6}$ Dalton (11.8\%) and $1.282 \times 10^{4}$ Dalton (88.2\%). Other fractions indicated a lower molecular weight in the range of $\sim 10^{3}$ Dalton.

\subsection{Production in Air-Lift Bioreactor}

Table 3 showed the biomass and productivity in the air-lift bioreactor. The highest productivity of biomass in air-lift bioreactor with $2.5 \mathrm{~L}$ working volume of Pleurotus flabellatus is $2.25 \mathrm{~g} / \mathrm{L} /$ day at volume per volume per min (vvm) 0.8. The air inlet flow rate did not seem to affect the productivity of the biomass very much. The yield of biomass against substrate used (glucose consumption) $Y_{b / s}$ was $0.78 \mathrm{~g} / \mathrm{g}$.

\section{Discussion}

The mushroom species $P$. flabellatus was chosen due to its consistency and highest production rate of mycelium at the rate of $0.180 \mathrm{~g} / \mathrm{L} /$ day. For the media screening, MCM was chosen with highest productivity at the rate of

Table 1. The production rate calculation for different media.

\begin{tabular}{cccc}
\hline Fermentation days & MCM (g/L/day) & YM (g/L/day ) & PE (g/L/day) \\
\hline 6 & $0.213 \pm 0.090$ & $0.133 \pm 0.156$ & $0.122 \pm 0.01$ \\
8 & $0.263 \pm 0.100$ & $0.165 \pm 0.065$ & $0.165 \pm 0.018$ \\
10 & $0.311 \pm 0.036$ & $0.220 \pm 0.070$ & $0.179 \pm 0.040$ \\
12 & $0.294 \pm 0.008$ & $0.244 \pm 0.061$ & $0.181 \pm 0.061$ \\
14 & $0.155 \pm 0.066$ & $0.274 \pm 0.099$ & $0.176 \pm 0.032$ \\
\hline
\end{tabular}

Table 2. The yield of $\beta$-glucan from crude extract of $P$. flabellatus.

\begin{tabular}{cccc}
\hline Species & Total glucan $(\mathrm{mg} / 100 \mathrm{mg})$ & $\alpha$-glucan $(\mathrm{mg} / 100 \mathrm{mg})$ & $\beta$-glucan $(\mathrm{mg} / 100 \mathrm{mg})$ \\
\hline Mycelium of $P$. flabellatus & $17.54 \pm 2.91$ & $9.84 \pm 3.82$ & $7.70 \pm 1.11$ \\
\hline
\end{tabular}

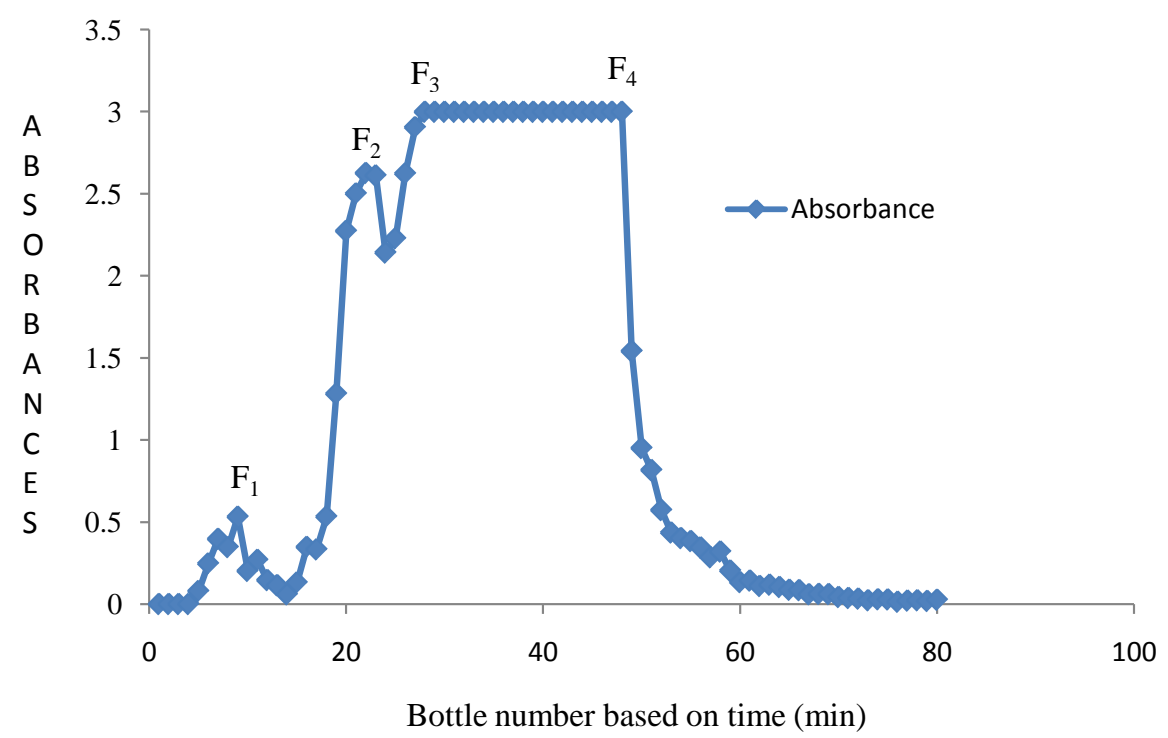

Figure 3. The reading of phenol sulphuric acid test from column chromatography of endopolysaccharides from Pleurotus flabellatus. 
Table 3. The productivity of Pleurotus flabellatus biomass production in air-lift bioreactor.

\begin{tabular}{ccccc}
\hline Air inlet flowrate (L/min) & vvm & Mycelium biomass $(\mathrm{g})$ & Reducing sugar $(\mathrm{g} / \mathrm{L})$ & Productivity $(\mathrm{g} / \mathrm{L} /$ day) \\
\hline 0.5 & 0.2 & $20.40 \pm 1.98$ & $10.69 \pm 1.71$ & $2.04 \pm 0.20$ \\
1.0 & 0.4 & $22.00 \pm 2.12$ & $8.30 \pm 0.61$ & $2.20 \pm 0.21$ \\
1.5 & 0.6 & $20.85 \pm 1.63$ & $10.49 \pm 2.36$ & $2.09 \pm 0.16$ \\
2.0 & 0.8 & $22.50 \pm 4.10$ & $8.49 \pm 1.19$ & $2.25 \pm 0.41$ \\
\hline
\end{tabular}

$0.311 \mathrm{~g} / \mathrm{L} / \mathrm{day}$. In a similar study for Ganoderma resinaceum in $250 \mathrm{ml}$ shake flask using MCM medium, the biomass production rate obtained was $0.333 \mathrm{~g} / \mathrm{L} /$ day [10]. Another study indicated that the maximum biomass produced for Pleurotus sajor caju in shake flask was $6.5 \mathrm{~g} / \mathrm{l}$ in 10 days (0.650 g/L/day) using deproteinized whey, diammonium phosphate and yeast extract as fermentation medium [11].

For the $\beta$-glucan content using assay kit by Megazyme, a paper reported that the $\beta$-glucan in endopolysaccharides of Lentinus squarrosulus was $11.36 \pm 0.27(\% \mathrm{w} / \mathrm{w})$ for the hot water extract in submerged culture fermentation [12]. Another paper reported the $\beta$-glucan content obtained from the fruit body of G. applanatum, T. versicolor, L. edodes, and G. lucidum to be 16.0, 33.4, 41.2 and $41.4 \mathrm{~g} / 100 \mathrm{~g}$, respectively using dry weight of dialyzed crude extract [13]. This researcher used higher purity of crude extract using dialysis technique.

The high molecular weight in the order of $10^{6}$ with $3.058 \times 10^{6}$ Dalton $(11.8 \%)$ and $1.282 \times 10^{4}$ Dalton (88.2\%) obtained from $P$. flabellatus indicated this compound has the potential to be explored for anti-tumor as reported by Akramiene and coworkers [14] regarding the application of high molecular weight $\beta$-glucan. Another report showed that the insoluble glucan obtained from yeast separated using size exclusion chromatography also has two peaks with molecular weight of $1 \times 10^{6}$ Da (1\% of total mass) and $1.5 \times 10^{4}$ Da (99\% of total mass) [15].

For the production of biomass using air-lift bioreactor, the value of $2.25 \mathrm{~g} / \mathrm{L} /$ day reported in this experiment is in the same range as reported by Cho and coworkers [16]. The report showed that for Tremella fuciformis in $5 \mathrm{~L}$ airlift bioreactor, the maximum dry weight obtained was $10.30 \mathrm{~g} / \mathrm{l}$ at days 5 (productivity $2.06 \mathrm{~g} / \mathrm{L} /$ day). For the same species using stirred-tank bioreactor, the cell dry weight obtained was 8.83 g/L (productivity 1.77 g/L/day) [16].

In another study using stirred tank fermentor, the productivity of Pleurotus sajor-caju biomass was 0.648 g/L/day, with 3 L working volume, agitation speed of 150 rpm, and aeration rate of 2 vvm [17].

\section{Conclusions}

The species $P$. flabellatus has the highest biomass productivity $(0.180 \mathrm{~g} / \mathrm{L} /$ day $)$ with potato extract as the crude media. Enhanced biomass productivity (0.311 g/L/day) was achieved with MCM. The yield of beta glucan from submerged culture fermentation of $P$. flabellatus was $7.70 \pm 1.11 \mathrm{~g} / 100 \mathrm{~g}$. The productivity of biomass in airlift bioreactor was $2.25 \mathrm{~g} / \mathrm{L} /$ day and approximately 12.5 times higher compared to the initial value. The fourth fraction $\mathrm{F}_{4}$ gave the highest molecular weight with $3.058 \times 10^{6}$ Dalton $(11.8 \%)$ and $1.282 \times 10^{4}$ Dalton (88.2\%).

The $\beta$-glucan (1.3:1.6) from Pleurotus flabellatus species has the potential to be produced in submerged culture fermentation at a higher productivity. The quantity and quality of the $\beta$-glucan can be purified further and tested for its effectiveness towards anti-tumor application. The high molecular weight produced from this research can be analyzed for a single compound and determine its exact molecular structure. The air-lift bioreactor can be custom-made and produced at a cheaper price locally.

\section{Acknowledgements}

I would like to thank MOSTI for the grant 02-03-01-SF0157 supporting this research and the staff from Nuclear Malaysia, Mr. Hassan Hamdani Hassan Mutaat, Mr. Mohd Meswan Maskom, Ms Nurul Shahnadz Amir Hamzah, Ms Liyana Mohd Ali Napia, Industrial Biotechnology Research Group from UKM and Herbal Medicine Research Centre, IMR for their technical support.

\section{References}

[1] Wasser, S.P. (2002) Medicinal Mushrooms as a Source of Antitumor and Immunomodulating Polysaccharides. Applied Microbiology and Biotechnology, 60, 258-274. http://dx.doi.org/10.1007/s00253-002-1076-7 
[2] Zhang, M., Cui, S.W., Cheung, P.C.K. and Wang, Q. (2007) Antitumor Polysaccharides from Mushrooms: A Review on Their Isolation Process, Structural Characteristics and Antitumor Activity. Trends in Food Science \& Technology, 18, 4-19. http://dx.doi.org/10.1016/j.tifs.2006.07.013

[3] Ooi, V.E.C. and Liu, F. (2000) Immunomodulation and Anti-Cancer Activity of Polysaccharide-Protein Complexes. Current Medicinal Chemistry, 7, 715-729. http://dx.doi.org/10.2174/0929867003374705

[4] Smith, J.E., Rowan, N.J. and Sullivan, R. (2002) Medicinal Mushrooms: Their Therapeutic Properties and Current Medical Usage with Special Emphasis on Cancer Treatments. University of Strathclyde \& Cancer Research, UK.

[5] Mizuno, T. (1999) The Extraction and Development of Antitumor-Active Polysaccharides from Medicinal Mushrooms in Japan. International Journal of Medicinal Mushroom, 1, 9-29. http://dx.doi.org/10.1615/IntJMedMushrooms.v1.i1.20

[6] Bae, J.T., Sinha, J., Park, J.P., Song, C.H. and Yun, J.W. (2000) Optimization of Submerged Culture Conditions for Exobiopolymers Production by Paecilomyces japonica. Journal of Microbiology and Biotechnology, 10, $482-487$.

[7] Choi, D.B., Lee, J.H., Kim, Y.S., Na, M.S., Choi, O.Y., Lee, H.D., Lee, M.K. and Cha, W.S. (2011) A Study of Mycelial Growth and Exopolysaccharides Production from a Submerged Culture of Mycoleptodonoides aitchisonii in Air-Lift Bioreactor. Korean Journal of Chemical Engineering, 28, 1427-1432. http://dx.doi.org/10.1007/s11814-011-0109-2

[8] Mizuno, T., Ando, M., Sugie, R., Ito, H., Shimura, K., Sumiya, T. and Matsuura, A. (1992) Antitumor Activity of Some Polysaccharides Isolated from an Edible Mushroom Ningyotake, the Fruiting Bodies and the Cultured Mycelium of Polyporous confluens. Bioscience Biotechnology, Biochemistry, 56, 34-41. http://dx.doi.org/10.1271/bbb.56.34

[9] Young, S.H. and Castranova, V. (2005) Toxicology of 1-3-Beta Glucans: Glucan as a Marker for Fungal Exposure. CRC Press, Boca Raton. http://dx.doi.org/10.1201/9780203020814

[10] Kim, H.M., Paik, S.Y., Ra, K.S., Koo, K.B., Yun, J.W. and Choi, J.W. (2006) Enhanced Production of Exopolysaccharides by Fed-Batch Culture of Ganoderma resinaceum. The Journal of Microbiology, 44, 233-242.

[11] Mukhopadhyay, R., Chatterjee, S., Chatterjee, B.P. and Guha, A.K. (2005) Enhancement of Biomass Production of Edible Mushroom Pleurotus sajor-caju Grown in Whey by Plant Growth Hormones. Process Biochemistry, 40, 1241-1244. http://dx.doi.org/10.1016/j.procbio.2004.05.006

[12] Ahmad, R., Muniandy, S., Abdullah Shukri, N.I., Alias, S.M.U., Abdul Hamid, A., Wan Yusoff, W.M., Senafi, S. and Daud, F. (2014) Antioxidant Properties and Glucan Compositions in Various Crude Extract from Lentinus squarrosulus Mycelia Culture. Advances in Bioscience and Biotechnology, 5, 805-814. http://dx.doi.org/10.4236/abb.2014.510094

[13] Kozarski, M., Klaus, A., Niksic, M., Vrvic, M.M., Todorovic, N., Jakovljevic, D. and Van Griensven, L.J.L.D. (2012) Antioxidative Activities and Chemical Characterization of Polysaccharide Extracts from the Widely Used Mushrooms Ganoderma applanatum, Ganoderma lucidum, Lentinus edodes and Trametes versicolor. Journal of Food Composition and Analysis, 26, 144-153. http://dx.doi.org/10.1016/j.jfca.2012.02.004

[14] Akramiene, D., Kondrotas, A., Didziapetriene, J. and Kevelaitis, E. (2007) Effects of $\beta$-Glucans on the Immune System. Medicina (Kaunas), 43, 597-606.

[15] Tzianabos, A.O. (2000) Polysaccharide Immunomodulators as Therapeutic Agents: Structural Aspects and Biologic Function. Clinical Microbiology Reviews, 13, 523-533. http://dx.doi.org/10.1128/CMR.13.4.523-533.2000

[16] Cho, E.J., Oh, J.Y., Chang, H.Y. and Yun, J.W. (2006) Production of Exopolysaccharides by Submerged Mycelia Culture of a Mushroom Tremella fuciformis. Journal of Biotechnology, 127, 129-140. http://dx.doi.org/10.1016/j.jbiotec.2006.06.013

[17] Kim, S.W., Hwang, H.J., Park, J.P., Cho, Y.J., Song, C.H. and Yun, J.W. (2002) Mycelial Growth and Exo-Biopolymer Production by Submerged Culture of Various Edible Mushrooms under Different Media. Letters in Applied Microbiology, 34, 56-61. http://dx.doi.org/10.1046/j.1472-765x.2002.01041.x 